\title{
IDENTIDADES COLECTIVAS Y MOVIMIENTOS DE MUJERES El caso de "Madres Contra la Droga"*
}

\author{
CELIA VALIENTE FERNÁNDEZ \\ Universidad Carlos III, Madrid.
}

\author{
PALABRAS CLAVE ADICIONALES \\ ADDITIONAL KEYWORDS \\ Movimientos sociales, Género, Drogas, España. \\ Social Movements, Gender, Drugs, Spain.
}

RESUMEN. El presente artículo argumenta que los movimientos de madres no sólo persiguen principalmente objetivos materiales, como se desprende de parte de la literatura académica sobre movimientos sociales, sino también la construcción de una identidad colectiva. Su autora analiza la identidad forjada en los grupos de Madres Contra la Droga, activos en España desde los años ochenta.

ABSTRACT. This article focuses on the Spanish social movement "Mothers Against Drugs" which has been active since the 1980s. One of the chief aims of mothers' movements has been the construction of a collective identity more than the achievement of material objectives as it would be assumed by the academic literature on social movements. This article analyzes the goals of such a movement and demonstrates the prominence of forging collective identity within those goals.

\footnotetext{
* Este artículo es uno de los resultados de mi participación en un proyecto de investigación titulado Gender, Political Identities and Recognition Struggles in Contemporary Societies, dirigido por Barbara Hobson y patrocinado por la Bank of Sweden Tercenary Foundation. Desearía agradecer a todos los miembros del equipo de investigación y a Gracia Trujillo sus valiosos comentarios a versiones anteriores de este escrito, que fueron presentadas en congresos y seminarios realizados en Dinamarca, Estados Unidos, Francia, la República Checa y Suecia. Myra Marx Ferree y Fiona Williams me proporcionaron inestimables consejos respecto a la literatura secundaria. Parte del material proviene de: Valiente Fernández (en prensa). El trabajo empírico de esta investigación fue parcialmente financiado por la Dirección General de la Mujer de la Comunidad Autónoma de Madrid. Mención especial merecen todas las personas a quienes entrevisté, ya que generosamente compartieron conmigo sus experiencias y reflexiones, a fin de hacerme comprender las complejidades de los problemas sociales y las dificultades de la acción colectiva. El artículo está dedicado a todas las Madres Contra la Droga, como muestra de reconocimiento y respeto por su incansable movilización en favor de los drogodependientes. E-mail: valiente@polsoc.uc3m.es
}

Revista Internacional de Sociología (RIS)

Tercera Época, $n^{\circ} 29$, Mayo-Agosto, 2001, pp. 35-65. 
RIS

REVISTA INTERNACIONAL DE SOCIOLOCIA

No 29, Mayo - Agosto, 2001

Los movimientos de madres suelen ser conceptualizados por la literatura académica como actores colectivos que persiguen la mejora de las condiciones económicas en que viven sus familias o sus comunidades. Sin embargo, el análisis de algunas asociaciones de madres contra la droga en España documenta que la construcción de una identidad colectiva (ideas forjadas en la movilización social y compartidas por los miembros de un grupo organizado acerca de quiénes son ellos) constituye una parte muy importante de las acciones emprendidas por estos movimientos. Por ello, considero que es necesario reconsiderar su clasificación como entes colectivos interesados, sobre todo, en alcanzar objetivos materiales ${ }^{1}$.

He organizado el escrito en seis secciones. En la primera presento el marco analítico utilizado para desarrollar esta investigación, basado en una revisión sucinta de los estudios sobre las asociaciones de madres y los movimientos sociales en general. En la segunda explico cómo he seleccionado el caso de estudio y qué fuentes de investigación he utilizado. Las siguientes secciones contienen un análisis de la identidad de madre contra la droga fraguada en las organizaciones que aquí investigo. En la tercera describo cómo uno de los primeros pasos dados por muchos miembros de estos movimientos ha consistido en desvelar ante otras personas la condición de progenitora de un drogodependiente, y en desprenderse del sentimiento de culpa personal por la toxicomanía de un hijo. En la cuarta propongo que la definición de maternidad forjada en la actividad asociativa de los grupos que examino no es estrictamente biológica, ya que algunas mujeres sin hijos drogodependientes han participado de manera muy activa en las organizaciones ahora analizadas. En la quinta muestro que la auto-percepción de madre contra la droga implica en muchos casos la conciencia de formar parte de un estrato social modesto. En la sexta y última argumento que una de las dimensiones de la identidad de estas madres consiste en definirse a sí mismas como expertas en toxicomanías.

\section{MARCO ANALÍTICO}

Las investigaciones académicas han estudiado los movimientos de madres (también llamados "maternalistas" o "maternales") sobre todo en Latinoamérica

\footnotetext{
${ }^{1}$ Las investigaciones sobre movimientos sociales, entre ellas ésta, en ocasiones tienden a presentarlos como actores unitarios, cuando en realidad no lo son. Además, a veces son proclives a describir los movimientos como si de seres animados se tratara: por ejemplo, cuando afirman que "el movimiento X persiguió el objetivo A", o "el movimiento $\mathrm{Y}$ defendió la postura B". Conviene recordar que este tipo de expresiones constituyen recursos estilísticos, ya que sólo las personas pueden perseguir objetivos o defender posturas.
} 
(Alvarez, 1990; Jaquette, 1994; Jaquette y Wolchik, 1998; Molyneaux, 1985; Schirmer, 1993), donde en las últimas décadas se han fundado organizaciones de madres y de parientes (femeninos) de víctimas de violaciones de derechos humanos. El grupo más conocido es el de las Madres de la Plaza de Mayo en Argentina, si bien han aparecido asociaciones de este tipo en otros países. Otra corriente de movimientos "maternalistas" latinoamericanos está compuesta por las agrupaciones de mujeres que en los barrios pobres se han movilizado para mejorar las condiciones de vida de sus familias y comunidades. Los movimientos maternales han surgido también en las sociedades contemporáneas de otros lugares (Miles, 1996) tan distantes entre sí como América del Norte o Sudáfrica (Christiansen-Ruffman, 1995; Kaplan, 1997; Pardo, 1995). Los historiadores han investigado, además, movilizaciones de esta clase en épocas pasadas y en distintos países, entre ellos, España (Kaplan, 1982; 1999). Al verse impedidas las mujeres para desempeñar las tareas a ellas asignadas según la división tradicional del trabajo por razón de género ${ }^{2}$ (tales como proporcionar alimentos, vestido, cobijo y asistencia médica a sus hijos), utilizaron el prestigio social que les confería su condición de madres para plantear reivindicaciones a las autoridades: por ejemplo, que los precios de los alimentos básicos no alcanzaran niveles desorbitados. En otros países occidentales, durante el período formativo de sus Estados de bienestar, ciertas agrupaciones de mujeres demandaron, en los mismos términos, la elaboración de políticas sociales para madres y niños (Gordon, 1994; Koven y Michel, 1990; 1993; Muncy, 1991; Pedersen, 1993; Skocpol, 1992; Skocpol et al., 1993).

En los años ochenta se desarrollaron diversas herramientas conceptuales para estudiar los movimientos maternalistas. Molyneaux (1985), analizando la Nicaragua sandinista, propuso que las mujeres en ocasiones se movilizan persiguiendo lo que ella denominó "intereses prácticos de género". Éstos surgen inductivamente de las condiciones de vida del sector femenino en cada sociedad, caracterizadas por un peculiar reparto de las tareas entre personas de ambos géneros. Los intereses prácticos suelen reflejar necesidades inmediatas, tal como son percibidas por las propias mujeres. Por ejemplo, dado que éstas se encargan casi siempre del aprovisionamiento del hogar y del cuidado de sus miembros, suelen estar interesadas ( $\mathrm{y}$ tienden a apoyar) las políticas públicas que aseguran una oferta de comida a precio asequible y la provisión de servicios sanitarios

\footnotetext{
${ }^{2}$ La literatura feminista habla de "géneros" en vez de "sexos" al denominar a los hombres y/o a las mujeres en su conjunto, por entender que la palabra "sexos" hace referencia principalmente a las diferencias fisicas entre unos y otras, mientras que el vocablo "géneros" alude sobre todo a las disimilitudes de origen social, educativo, cultural y económico que entre ambos existen, y que, según dicha literatura, son las fundamentales (y no las de origen biológico).
} 
para su familia. Molyneaux afirma que son distintos grupos de mujeres quienes formulan, ellos mismos, sus intereses prácticos de género. En la misma línea, Kaplan (1982), estudiando episodios de movilización en Barcelona en los años veinte, acuñó el concepto de "conciencia femenina" para describir el conjunto de ideas, percepciones y creencias que impulsan a las mujeres a formar parte de movimientos sociales persiguiendo lo que Molyneaux llamó "intereses prácticos de género".

Por contraste, según Molyneaux, los "intereses estratégicos de género" se deducen a partir del estudio de la subordinación de las mujeres en una sociedad determinada, y de la comparación con una (teórica) más igualitaria. Como objetivos estratégicos para superar la desigualdad en que se encuentra el sector femenino de la población propone la autora, a modo de ejemplo, la abolición de la división sexual del trabajo, la remoción de la discriminación institucionalizada o la adopción de medidas contra la violencia masculina perpetrada contra las mujeres.

Reflexionando sobre los movimientos sociales en general (y no sobre los maternalistas en particular) Fraser (1995) ha propuesto, en un escrito de gran influencia, que en nuestra época post-socialista continúan existiendo grupos que padecen privaciones materiales debido a que ocupan una posición subordinada en las estructuras socio-económicas. Soportan, además, un desprecio generalizado hacia sus identidades específicas como colectivo, esto es, sufren vejaciones que podríamos llamar culturales o simbólicas. Para escapar de esta doble situación de desventaja dichos grupos necesitan, por una parte, lo que la mencionada autora denomina la "redistribución" (de los recursos materiales a su favor) y, por otra, el "reconocimiento", es decir, la valoración positiva de sus características personales. Al argumentar así, Fraser rebatía la hipótesis defendida por otros autores (Honneth, 1992; Taylor, 1992; Young, 1990), según la cual en las sociedades contemporáneas un número creciente de colectivos discriminados se han venido centrando progresivamente en el objetivo de intentar modificar las normas culturales sesgadas en su contra y lograr la estima social hacia sus rasgos identitarios (por ejemplo, su orientación sexual, su pertenencia a un grupo étnico determinado o a uno de los dos géneros), considerando de segundo orden la meta de tratar de mejorar sus condiciones materiales de vida.

En este artículo argumento que resulta muy útil poner en relación los hallazgos de los dos cuerpos de literatura (acerca de los movimientos maternalistas y sobre la disyuntiva "redistribución"/"reconocimiento"). El debate acerca de la "redistribución" y el "reconocimiento" nos ayuda a darnos cuenta de que buena parte de la investigación académica sobre los movimientos maternales tiende a describir muchos de ellos como grupos organizados en defensa de la mejora de las condiciones económicas ${ }^{3}$. Las reivindicaciones redistributivas son normalmente planteadas cuando estas madres demandan los medios materiales que les permiten administrar sus hogares, dar de comer a sus hijos y cuidar a 
sus familiares. Por lo general, los investigadores han prestado poca atención a los aspectos ligados al "reconocimiento" de las movilizaciones de los grupos de madres. ¿Ello es así porque las luchas culturales no forman parte de las agendas reivindicativas de estos movimientos? ¿O sí forman parte de ellas las demandas ligadas a los aspectos indentitarios, pero los académicos han subestimado su importancia?

\section{SELECCIÓN DEL CASO DE ESTUDIO Y FUENTES}

En este trabajo trato de responder a las preguntas anteriores valiéndome de un estudio de caso: los grupos de madres contra la droga, que han aparecido en España principalmente desde los años ochenta. Según Lijphart (1971:691), si bien el diseño ideal de investigación es el formado por la comparación entre dos o más casos, el análisis de un único caso puede resultar revelador, dado que el investigador tiene la posibilidad de examinarlo exhaustivamente, incluso si sus recursos son limitados, como sucede en esta ocasión.

Por lo que se refiere a las fuentes utilizadas, no conozco ningún trabajo académico sobre las asociaciones de madres contra la droga, por lo que este estudio se basa en material primario y no en secundario. La principal fuente consiste en entrevistas semi-estructuradas a veinte miembros de estos grupos y a dos trabajadoras sociales (contratadas por estas asociaciones) realizadas en mayo y junio de 1999 en Madrid y en un municipio cercano (Fuenlabrada) 4 . La mayoría de las personas pertenecientes a asociaciones de madres entrevistadas para este trabajo ocupan o han ocupado puestos directivos en dichas organizaciones (los cargos de presidenta, vice-presidenta, tesorera y vocal de la junta directiva). He conversado con estas mujeres, y no con otras, principalmente por dos razones. $\mathrm{Al}$ contactar con algunas agrupaciones me fue sugerido que entrevistase a quienes estaban entonces situadas en cargos, porque éstos suelen implicar el cometido de representar a la organización en distintos contextos, entre otros las relaciones con los investigadores. Además, frecuentemente las personas en puestos de responsabilidad en estos grupos suelen contar con un período de militancia más dilatado que el de los restantes miembros. Este largo intervalo

\footnotetext{
${ }^{3}$ La excepción a esta generalización serían las agrupaciones movilizadas a favor del respeto de los derechos humanos.

${ }^{4}$ Las limitaciones de tiempo y de financiación me han hecho circunscribir el trabajo de campo a estos lugares, pese a que existen agrupaciones de madres contra la droga en otros puntos geográficos de España. Las entrevistas reflejan entonces las experiencias y opiniones de las madres de Madrid y alrededores acerca de las cuestiones de que trata este artículo.
} 
temporal incrementaba la utilidad de las entrevistas de modo acusado, ya que a partir de ellas he reconstruido sobre todo las diversas experiencias de participación dentro de las organizaciones, algunas de las cuales se gestaron hace casi dos décadas 5 .

Cuando en el cuerpo del artículo transcribo literalmente algunos fragmentos de las entrevistas, los nombres de las personas son siempre ficticios, a fin de proteger su anonimidad (ello me fue pedido explícitamente en tres casos). Por el contrario, los nombres de las ocho asociaciones de madres contra la droga a las que pertenecen las mujeres con quienes conversé son reales y aparecen al final del artículo ${ }^{6}$. En los barrios donde surgieron y permanecen activas estas agrupaciones, así como en los medios de comunicación y la sociedad en general, los miembros de estos grupos y sus propias organizaciones son conocidas con la expresión de "madres contra la droga" y, en algunos contextos, simplemente como "las madres". Estas denominaciones son las empleadas también en este trabajo, si bien los nombres formales de las agrupaciones con frecuencia no mencionan el término "madres". Otras fuentes utilizadas para elaborar este artículo han sido los documentos publicados y no publicados de estas asociaciones, además de dossiers de prensa.

Este artículo no es una historia sintética del movimiento de las madres contra la droga en España, sino un análisis de una de las dimensiones de dicha movilización: la formación de identidades colectivas. En esta investigación utilizo la definición de movimiento social elaborada por Diani (1992:7) como un conjunto de redes formales e informales de individuos, grupos $y / u$ organizaciones que comparten ciertas ideas e identidad, se movilizan con objeto de promover (o detener) el cambio social ( $\mathrm{y}$ al hacerlo encuentran oposición), utilizando preferentemente formas políticas no convencionales de actuación, por ejemplo, distintas modalidades de protesta. Este escrito tampoco es una historia de las organizaciones que forman parte hoy día del movimiento de las madres

\footnotetext{
${ }^{5}$ Soy consciente de que el criterio de selección de las entrevistas hace que cuente sólo con el testimonio de las personas que han militado durante más tiempo y más activamente en las asociaciones; tal vez sus experiencias, percepciones y valoraciones sean diferentes de las del resto de los miembros. Sin pretender infravalorar este sesgo, defiendo la elección realizada, porque esta investigación no es un estudio cuantitativo en el que pretendo describir con precisión las características de un grupo; trato, únicamente, de identificar tendencias y pautas de movilización de las madres contra la droga, sin ponderar estadísticamente su relevancia.

${ }^{6}$ Escogí estas ocho asociaciones para el estudio (y no otras) tratando de que el conjunto de agrupaciones analizado comprendiera organizaciones sitas en distintos barrios y fundadas en diferentes momentos cronológicos. Por razones obvias, hube de descartar grupos cuyos miembros no quisieron ser entrevistados o accedieron a ello, pero resultó imposible encontrar una fecha para hacerlo durante el período de realización del trabajo de campo.
} 
contra la droga. Suscribo la afirmación de que "los movimientos sociales no son organizaciones, ni siquiera unas de tipo particular; son redes de interacción entre distintos actores, que pueden incluir (o no) organizaciones formales" (Diani, 1992:13-14; traducción de Celia Valiente). Como explican Della Porta y Diani (1999:17), la distinción analítica entre los movimientos sociales y las organizaciones que los componen resulta esencial para entender el papel central que determinados individuos desempeñan en los movimientos. Éste ha sido el caso de algunas de las mujeres entrevistadas, quienes con su esfuerzo colectivo vertebraron la movilización de las madres contra la droga, antes de que se establecieran las organizaciones formales en la actualidad incluidas en ella.

\section{DESVELANDO LA CONDICIÓN DE MADRES DE DROGODEPENDIENTES}

En esta sección muestro que los primeros pasos dados por muchas mujeres que han formado parte de las asociaciones de madres contra la droga han estado relacionados con la identidad personal, esto es, con el acto de responder a la pregunta acerca de quién es uno mismo. En la interacción con los demás miembros de sus grupos, numerosas madres han desvelado ante otros individuos la condición de progenitoras de drogodependientes, han hablado extensamente acerca de tal estado y han conseguido liberarse, siquiera parcialmente, de la impresión de ser ellas mismas las culpables de la adicción a las drogas de sus descendientes.

Las agrupaciones iniciales de madres contra la droga surgieron sobre todo en barrios de clase trabajadadora y clase media-baja de algunas ciudades. La abrumadora mayoría de sus miembros eran mujeres (si bien un reducidísimo número de hombres ha participado en estos grupos). Casi todas eran madres de drogodependientes que habían comenzado a consumir drogas en la adolescencia o en la primera etapa de la edad adulta ${ }^{7}$. También han pertenecido a estas agrupaciones algunas mujeres que no eran madres, sino parientes de toxicómanos, por ejemplo, tías. Un tercer tipo (asimismo minoritario) de miembros lo constituían individuos que no tenían familiares adictos a las drogas. Casi todas las madres contra la droga de una misma asociación vivían en el mismo barrio.

Los primeros grupos de madres aparecieron en los años ochenta, generalmente ligados a algunas parroquias católicas; éste ha sido el caso de seis de las ocho

\footnotetext{
${ }^{7}$ En aquella época, la mayor parte de los hijos de las madres movilizadas de que trata este artículo consumía heroína, si bien más tarde se implantó la tendencia de combinarla con otras drogas. En la actualidad, el consumo de sustancias adictivas es más diverso e incluye (entre otras) heroína, cocaína y drogas de síntesis (por ejemplo el éxtasis).
} 
asociaciones examinadas para este artículo. Ello no resulta extraño, dada la implantación de la religión católica en España ${ }^{8}$, puesto que los estudios sobre movimientos sociales realizados en el ámbito internacional han enfatizado la importancia del entramado asociativo previo para explicar el surgimiento de la acción colectiva - por ejemplo, la centralidad de las iglesias en los orígenes del movimiento de los derechos civiles en Estados Unidos (McAdam, 1982). Algunas madres contra la droga habían participado previamente en asociaciones de diverso tipo ligadas a sus parroquias, donde aprendieron a disfrutar de la interacción con otros miembros y desarrollaron o afianzaron la creencia de que ciertos problemas se solucionan mejor con la acción concertada de varias personas que cuando los individuos se enfrentan a ellos en solitario; otras progenitoras, sin embargo, no contaban con semejante experiencia. Las parroquias constituían un lugar al que algunas madres se dirigían espontáneamente cuando descubrían la adicción a las drogas de sus hijos; les ofrecieron, entre otros recursos organizativos, una sede donde celebrar las reuniones. En algunas ocasiones los sacerdotes animaron a las madres de los drogodependientes a formar asociaciones; tal fue el caso de una de las mujeres entrevistadas:

Concha: "Aquí, en la parroquia de (...) no había nada. (...). Entonces aquí hubo una asamblea muy grande, en la parroquia. Esto lo cogió un sacerdote llamado Javier. Entonces me llamó a mi casa y dijo que aquí se iba a formar una asociación, que si yo creía conveniente. Yo entonces venía muy dolida, porque yo ya venía de perder a mi hijo [drogodependiente]. Entonces una señora de mi casa, de enfrente de mi casa, como tres personas fundamos esta asociación, tres madres con problema de droga (...). Esto, al ver que ya se iba haciendo con gente, aquí en la parroquia, hubo una asamblea grande, porque al enterarse este señor Javier, Javier sacerdote, se enteró por un tal Jerónimo que hubo aquí, que él el problema de mi casa lo ha sabido siempre. Y entonces me llamó a mi casa y me dijo que si yo quería entrar en esta asociación. Y entonces le dije 'Mira, yo estoy muy dolida, y me siento.... 'Bueno, pero eres una persona que has luchado mucho y sabes lo que es la droga'.

Entrevistadora: ¿Por qué tenías cierta reticencia a fundar la asociación, Concha? ¿Porque estabas ya cansada del problema?

Concha: No estaba cansada sino que yo, ahí me cayó [en la droga] el otro hijo. ¿No me entiendes?

\footnotetext{
${ }^{8}$ Una amplia mayoría de españoles se declaran católicos ( $85 \%$ en marzo de 2000). Aunque el número de católicos practicantes es bastante más reducido, sigue siendo considerable: en marzo de 2000 la quinta parte de quienes se definían como católicos afirmaban que "asistían a misa u otros oficios religiosos, sin contar las ocasiones relacionadas con ceremonias de tipo social, por ejemplo, bodas, comuniones o funerales", casi todos los domingos y festivos, mientras que alrededor del $3 \%$ lo hacían varias veces a la semana (Centro de Investigaciones Sociológicas, 2000).
} 
Las agrupaciones iniciales proporcionaron a las madres un ámbito donde pudieron hablar acerca de la drogodependencia de sus hijos, puesto que este tipo de comunicación les estaba vedado a muchas de ellas en otros círculos, incluidos, en ocasiones, el familiar. Una de las madres describía esta situación:

Juana: "Al juntarte con otras personas que tienen tu problema, ayuda en ese aspecto no tienes, de decir que te van a solucionar el panorama, porque no te lo van a solucionar. Pero son personas que están con tu problema, y te escuchan, o sea, hablar, puedes hablar. Porque entonces es que no podías hablar de ello con nadie (...) te sentías aislada, no, aisladísima, te digo que hasta la familia. (...). Con la familia no puedes hablar porque te están dando de lado (...). La familia te deja, las vecinas te dejan (...) porque si yo te explico, las hermanas de mi marido se enteraron antes que yo, y en lugar de decírmelo, la una se llama a la otra: 'Oye, ¿no sabes qué? Pues que se ha metido a la droga' (...), en vez de coger y decir: 'Oye, mira al chico, que he visto una cosa muy rara'. Aunque no me lo digan claramente; pero a mí jamás me dijeron nada".

Otra de las mujeres entrevistadas añadía más información acerca de las reacciones hostiles o indiferentes de los familiares ante la drogadicción de su hijo, y sostenía que resultaba muy dificil para las madres de los toxicómanos conversar sobre la cuestión con muchos individuos porque no les entendían, debido a que no habían sufrido personalmente ese problema:

Concha: "Lo primero, cuando la familia se enteran que tienes un hijo drogadicto, lo primero que le hacen es mirar por la mirilla y no abrirle. No hay regla sin excepción ¡ojo! Porque piensan (...) tienen miedo. Tienen miedo porque tú, en un momento dado te encuentras con un apuro muy grande, y te llama tu cuñada y: ' $i$ Ay! Pues he dejado el monedero y me ha quitado...' Y entonces ella, si va mi hijo, lo primero que hace es esconder el monedero.

Entrevistadora: Pero ¿apoyan a la madre o...?

Concha: Bueno, pues mira, nada más que te dicen, como a mí: 'Mujer, ten paciencia. ¡Qué pena! ¡Un hijo tan bueno! ¡Unos hijos tan educados!' Y punto.

Entrevistadora: ¿Pero tú no puedes explayarte y hablar de tu problema?

Concha: No, porque no te entienden. No conocen el mundo de la droga. Una persona ahora mismo, tú fijate lo que te voy a decir, que no tenga el problema, por mucho que quiera entenderme a mí, le cuesta mucho. Porque tú ves las cosas de otra forma. Tú ves la droga como un vicio (...). Mi cuñada lo ve como un vicio, que no quiere trabajar, porque es lo más cómodo, porque los padres no los han entendido, no los han escuchado (...)". 
Ello nœ obstante, algunas madres sí habían podido tratar el tema con sus ramiliares. Según explicaba una de ellas:

Encarnación: "Sí, hay gente que sí puede hablar porque entiende. Nosotros somos diez hermanos, y mis hermanos me apoyaban mucho, sabían que tenía este problema y me apoyan mucho.

Entrevistadora: ¿Pero no es lo normal?

Encarnación: No, pero, o sea, es que yo también soy especial para mis hermanos, bueno, dóncie me ponen y todo...

Entrevistadora: ¿Eres la mayor?

Encarnación: No, soy la segunda. Pero bueno, ahí te apoyan, te apoya toda la familia (...). Pero a otra familia no se lo puedes contar. Pero yo sí lo contaba a mis hermanos".

Es preciso destacar que los grupos de madres contra la droga están compuestos por personas muy diversas, la mayoría de las cuales sólo comparten algunas de las siguientes características: ser mujer (aunque un ínfima minoría de miembros son hombres), ser de mediana edad, proceder de la clase trabajadora o media-bajc. (en algún caso de un estrato social algo más acomodado), pero no de grupos marginales, tener hijos drogodependientes (aunque en algunos casos no sucede así) y vivir en el mismo barrio (con excepciones). Sus miembros difieren en muchas otras cuestiones, por ejemplo, en términos de ideología política o grado de religiosidad. Como sintetizaba una de las madres [Matilde]: "Estamos muy lejos una gente de otra". Por ello, el investigador puede encontrar pautas que describen lo que sucede a algunas o a muchas de las personas entrevistadas (tales como la imposibilidad para hablar de la drogodependencia de sus hijos), pero no a todas ellas.

Ciertas madres necesitaban no sólo conversar con otras acerca de la toxicomanía de sus hijos, sino liberar tensiones emocionales por medio del llanto. Tal como lo describía el siguiente diálogo:

Benigna: "Bueno, yo vine aquí [al grupo], y me tiré tres meses llorando. Venía; '¡Ya viene la llorona!' [decían las otras madres].

Entrevistadora: Bueno, te debía hacer mucha falta ¿no?

Encarnación: No, tanto llorar no [con ironía] 
Una primera reacción de muchas progenitoras, cüando se enteraron de la drogodependencia de sus hijes, consistió en culparse a sí mismas de tal adicción. Por ejemplo, una de las mujeres entrevistadas pensó que la convivencia con un padre alcohólico tal vez hubiera influido negativamente en la formación del carácter de su hijo:

Juana: "Eso [el sentimiento de culpabilidad] es matemático, todas [las madres]. (...) yo los he criado [a los hijos] con muchísimo sacrificio, con mucho, porque la economía era pequeña (...) cuando eran pequeños. Lo has pasado mal para criarlos, porque estaba muy mal.

Entrevistadora: ¿Tú eras viuda?

Juana: No, cuando estoy hablando vivía mi marido, pero tenía prob!emas con éi, prioblemas porque era alcohólico, y claro, empiezas a dar vueitas: 'Pues ha sido por esto, y por esto y zor esto'. Yo he intentado evitar disgusios para que mis hijos no los vieran, pero es inevitable, y entonces empiezas a culparte de todo (...). Yo, en mi situación, mucha gente hubiera dejado a su marido (...) a mí no me ha maltratado, ¿eh? Yo no puedo decir eso, pero era alcohólico y broncas había todos los días porque (...). Bueno, y '¿cómo le dejo?' Porque, e' 'se, tenido momentos de hacerlo, de decirlo, $¿$ no? pero $¿$ cómo? $¡ Y$ en aquellos tiempos, an ac; tiempos! Porque hoy en día, ya lo ves, que la gente se separa a la mínima. (...). Perc e-.. aque... tiempos ¿quién era la que se divorciaba? (...) Porque mira yo (...) me iba por ahi y me - a ? uno tirado en la calle, todo roto, todo sucio, todo vomitado ...

Entrevistadora: ¿Y te imaginabas así a tu marido?

Juana: Y me decía, si él está en mi casa, no estará así. Y que vaya mi hijo por ahí y vea a su padre de esa manera... iPor lo menos dirá que ha visto a su padre borracho pero no que le ha visto tirado! Pero luego, después, cuando han pasado todas estas cosas dices: ' $¿ Y$ si lo hubiera dejado? A lo mejor mi hijo no hubiera visto todo este ... y hubiera reaccionado de otra manera'. Lo he pensado muchas veces, muchas veces. Porque mira, tendría, pues como ocho o diez años, y mi hijo falsificó la firma; falsificaba la firma de su padre (...). Porque en aquellos tiempos, luego es que también, es que ni los profesores ni nadie, çomo no llevara las notas firmadas por su padre, que las llevaba firmadas por su madre: '¿Qué pasa? ¿Es que eres huérfano?' Y él acabó falsificando la firma de su padre. Y llegó un momento que me lo dijo: 'Mamá, es que los profesores no te puedes hacer una idea, que si no tengo padre, que si soy huérfano, que nunca llevo las notas firmadas por mi padre (...)'. Es que decir que su padre era alcohólico, es

\footnotetext{
${ }^{9}$ Por petición expresa de ciertas madres, en algunas entrevistas conversé con varias de ellas, en vez de con una única persona.
} 


\section{RIS}

que él nunca decía que su padre estaba malo, ni que tenía eso, nada más que llevaba las notas firmadas por su madre (...). Y yo, pues lo acepté".

Otra madre relataba que llegó incluso a preguntar a su hijo drogodependiente si pensaba que sus padres eran los responsables de su adicción:

Mónica: "Yo siempre pensaba: ¿En qué hemos fallado? (...). A lo mejor, pues, él es distinto a los otros [hermanos], y ha sido muy fuerte para él la disciplina de esta casa, y luego, además, si ha tenido un poco de envidia del otro [de su hermano pequeño] (...). Me lo he preguntado muchas veces, y se lo he dicho a él, y me dice que no: 'Mamá, vosotros no tenéis culpa, he sido un golfo, un golfillo' dice. 'He sido un golfillo, he querido probar de todo, y nunca pensé que esto enganchara tanto y pudiera tener tan graves consecuencias, pero vosotros no tenéis culpa de nada".

Casi todas las mujeres entrevistadas que experimentaron un sentimiento de culpa por la adicción a las drogas de sus hijos consiguieron superarlo en las asociaciones de madres contra la droga. Una de ellas describía el proceso con las siguientes palabras:

Matilde: "Yo me sentía muy culpable, pensando que [en] la tarea más importante de mi vida, la de ser madre, como que había fallado ¿no? Es un sentimiento común, sí.

Entrevistadora: ¿El pensar que tu hijo es drogodependiente porque no has hecho algo bien?

Matilde: Sí, yo me había separado de su padre, había emprendido mi vida de libertad. Yo he trabajado siempre, y entonces he tenido ... pues, he estado menos con mis hijos, menos que las madres que están todo el día en su casa, todas esas cosas. ¡Pues me hacía yo unos líos en la cabeza...!"

Esta madre añadía en otro momento:

Matilde: "Mi hija y otro chaval fueron detenidos el mismo día en la calle, allí en la zona donde yo vivo. Y la madre del chavalito ese y el padre, los conozco de toda la vida, de jugar los niños en la calle. Y llevaban a sus hijos como pinceles. Mira, ves, ésa ha sido una mujer que no trabajaba. Ésa es una cosa que yo he aprendido aquí [en la asociación]. Ésa era una mujer que no trabajaba y [se] dedicaba de verdad, se iba con los niños al parque, jugaba con sus hijos, les ayudaba a hacer las tareas. Era una madre superordenada y superlimpia y super todo eso que yo, pues, no he tenido tiempo de serlo, porque trabajaba fuera, y he sido todo lo limpia que he podido, y he sido todo lo ordenada que he podido. Y aquí, pues, aprendí yo a ver que ni mejor ni peor. A su hijo le detuvieron junto con la mía, por hacer las mismas cosas que la mía, y por ser una persona exactamente tan adicta como la mía, y tan buena gente como la mía, o tan mala 
gente como la mía, sin ser ni mejor ni peor, ni ... y éramos del mismo círculo, o sea, todas esas cosas las he aprendido yo a valorar aquí [en la asociación]".

Por contraste, una reducida minoría de madres no pensó que la toxicomanía de sus hijos pudiera achacarse a la responsabilidad de ellas. Como explicaba una de las mujeres entrevistadas:

Adela: "Yo, la verdad, ese sentimiento [de culpa] no lo he tenido nunca. Yo, por mí, porque mis hijos estaban fuera de mi casa cuando han empezado, mis dos hijas estaban casadas, o sea que estaban viviendo sus propias vidas. (...) mi hija me ha echado en cara eso, que como les he tenido tan protegidos, todo se lo he hecho, y todo, pues que luego se han visto desvalidos. Que por supuesto han ido a eso [el consumo de drogas] porque han querido ¿no?, pero... mucho morro. (...). A mí es que me pidió ayuda mi hija. Yo no lo sabía. Casada desde hacía tres años y con una niña de once meses, cuando me pidió ayuda a mí".

En síntesis, en las asociaciones estudiadas muchos de sus miembros desvelaron su condición de madres de drogodependientes como no lo habían hecho en otros ámbitos. Pudieron además hablar sin tapujos de la toxicomanía de sus hijos con personas que, en su opinión, les entendían porque estaban inmersas en las mismas circunstancias. Las progenitoras terminaron pensando, también, que no eran responsables de que sus descendientes consumieran drogas, y que éstos se comportaban así por diversas causas, entre otras, la amplia y accesible oferta de sustancias adictivas existente en nuestra sociedad, la falta de información acerca de la adicción a las mismas e incluso por decisión personal. No obstante, de la valoración positiva que de estas dimensiones de la acción colectiva han hecho las madres entrevistadas no debe inferirse que la pertenencia a este tipo de asociaciones fuera fácil y gratificante desde el principio para todas ellas. En ocasiones, la inserción en la asociación resultó un proceso difícil por muchas razones, entre otras, la diversidad de pareceres de sus miembros sobre los más variados temas. Véase, a modo de ejemplo, cómo inicialmente una de las madres percibía las reuniones del grupo:

Matilde: "No me gustaban tampoco mucho las reuniones, me parecían vacías de sentido (...) me parecían las reuniones un poco sin sentido, la gente decía muchas cosas que a mí me sabían muy mal, porque a lo mejor se hablaba de tráfico y en contra de los traficantes, de los gitanos, y a mí eso me parecía racista (...)"10.

${ }^{10}$ Por petición expresa de cierta madres, en algunas entrevistas conversé con varias de ellas, en vez de con una única persona. 


\section{LA MATERNIDAD NO ES UNA CUESTIÓN MERAMENTE BIOLÓGICA}

Probablemente la dimensión de la identidad de los miembros de los grupos de madres contra la droga que con más intensidad les ha impulsado a la acción colectiva ha sido la maternidad. Sin embargo, como muestro a continuación, ésta no se ha definido en términos estrictamente biológicos en las movilizaciones para conseguir la "redistribución" y el "reconocimiento" a favor de los drogodependientes.

Es cierto que en España (y en los países mediterráneos), por comparación con otras sociedades occidentales, cuando los adolescentes y jóvenes consumen sustancias adictivas viven en el hogar de sus padres en porcentajes relativamente elevados. Ello se debe a que la edad de emancipación en España es alta en términos comparativos internacionales. En otoño de 1998, más de nuevê de cada diez (92\%) jóvenes de 15 a 24 años vivían con sus padres (o con uno de ellos) (Elzo et al., 1999: 486); igual le sucedía en la primavera de 1995 a la mitad (52\%) de las personas con edades comprendidas entre 25 y 29 años (Martín Serrano, 1996:5). La convivencia bajo el mismo techo con hijos toxicómanos probablemente haya llevado a muchas madres a implicarse en la búsqueda de soluciones para la drogodependencia de sus descendientes más que si no hubieran vivido con ellos. Según explicaba una de las entrevistadas, la preocupación de numerosas madres por estos hijos ha hecho que se sintieran constantemente en alerta:

Concha: "Ellos metidos en la droga, es un mundo, es un mundo. Pero tú, si no ha venido a comer, si se ha levantado, si se ha ido: '¡Dios mío! ¿Dónde habrá ido?' Si toca el teléfono: '¿Le habrá pasado algo?' Si llaman a la puerta: '¡Dios mío!' Ése es el convivir de una madre que tiene un hijo así (...). Y con todo y con eso, aun saliendo, los chicos que ya llevan tiempo [sin consumir drogas], la madre está siempre en vilo (...). Ese sufrimiento le llevaremos mientras que vivamos".

No obstante lo anterior, es importante resaltar que la condición de madre de un individuo adicto a las drogas y que vive con él puede terminar de varios modos. Los toxicómanos tal vez completen con éxito el proceso de desintoxicación y rehabilitación, lo que sucedió a diez hijos de las dieciséis madres (biológicas) entrevistadas para esta investigación. Los hijos drogodependientes en ocasiones fallecen, a causa de una sobredosis, de enfermedades diversas (entre ellas el SIDA), o en una lucha con la policía u otros cuerpos de seguridad del Estado; tal fue el caso de siete hijos de las dieciséis progenitoras biológicas con quienes conversé. Por último, las madres pueden expulsar de sus casas a los descendientes que consumen sustancias adictivas (véase infra) por una temporada o de manera definitiva; esto aconteció en el hogar de una minoría de madres entrevistadas. Algunas de estas mujeres, que no convivían ya con hijos toxicómanos, conti- 
nuaban participando de manera muy activa en las asociaciones, e incluso desempeñaban cargos directivos, lo cual apoya en parte la tesis de que la definición de la maternidad que ha movilizado a estas personas no ha sido en todos los casos únicamente biológica. Más bien ciertas mujeres se han asociado para solucionar el problema de sus hijos drogodependientes, en particular, pero también para ayudar a otras madres de drogodependientes, y/o para luchar, en general, contra la adicción a las drogas, la cual conforma un riesgo colectivo que afecta a muchos individuos (y a sus familiares) con quienes las madres no están ligadas por ningún vínculo biológico, pero en cuyo nombre también se han movilizado. Así lo explicaba una de ellas que continuaba militando en el grupo pese a que su hija hacía tiempo que se había desintoxicado y rehabilitado y una trabajadora social empleada por su asociación:

Aurora: "Sí, porque yo pienso que si yo no lo necesito, que algo siempre necesitaré, pero que si puedo ayudar al resto de las madres, pues, siempre es conveniente ¿no? Si la que viene, se quita el problema y no vuelve, llegará un día en que haya que cerrar la puerta.

Marta [trabajadora social]: Y ayuda mucho. Porque [Aurora] es un ejemplo de que se puede, de optimismo, porque Aurora es muy optimista. Y es un ejemplo que se valora mucho. La gente que viene nueva, que todavía lo tiene candente, y le sirve de ejemplo, de que luchando y con firmeza se puede (...).

Aurora: Pues siempre te hace algo decir: 'Pues mira, si ésta ha salido y ha sido por esta forma y esta condición, pues a ver si yo puedo, también, hacerlo'".

Es preciso añadir que posiblemente estas mujeres constituyen casos excepcionales, y la pauta general sea otra. Como explicaba una de las madres entrevistadas:

Encarnación: "Aquí a las personas, cuando se les arreglan las cosas y ya no tienen así problemas, o se las mueren los hijos, ya no quieren saber nada".

Como he mencionado antes, una minoría de quienes han pertenecido a estas asociaciones ni siquiera han tenido hijos toxicómanos. Por ejemplo, éste es el caso de dos líderes del grupo llamado "Madres Unidas contra la Droga" ("Madres Unidas" en el resto del artículo). Estas mujeres han argumentado que la drogodependencia es un problema social y no (o no sólo) personal, que puede afectar a los hijos de cualquier madre. Por ello, es factible para todas las mujeres, en teoría, luchar contra él y ser llamadas "madres contra la droga". Algunas, incluso, han explicado que esta definición de maternidad es susceptible hipotéticamente de aplicarse a los hombres, y han afirmado (con ironía) que en su organización se les da la bienvenida para que sean "madres" (Sara Nieto, 
comunicación personal, conversación telefónica con la autora de este artículo, 14 junio 1999). Una de las mujeres entrevistadas explicaba el gran respaldo que le proporcionaron dos miembros de su asociación sin hijos toxicómanos:

Concha: "Entonces yo ahí tuve un apoyo, que fueron dos personas que no tenían problema de droga (...). Dos personas que siguen en la asociación y que apoyan a una persona, cuando tú, verdaderamente, tienes un problema, y tienes a una persona que está yendo contigo a sitios donde a ella, verdaderamente, le tiene que costar. Voluntaria, sigue en la asociación, y lucha por la asociación.

Entrevistadora: ¿Eso os ha animado a las madres que teníais ese problema?

Concha: Bueno, a mí sobre todo en aquel momento sí me animó mucho. Y yo sôy una persona que como en aquel momento me ayudó, y ella dice que aprendió mucho, entonces yo sigo la amistad con ella ¿no?"

Utilizando esta definición de la maternidad como una condición social (aunque también, pero no exclusivamente, biológica), las madres contra la droga han venido reivindicando desde los años ochenta que el Estado (y en menor medida la sociedad) elaborara medidas para tratar a los drogodependientes (y que, según Fraser, constituirían actuaciones de "redistribución", o de transferencia de recursos a favor de grupos subordinados), entre otros, programas de desintoxicación y rehabilitación, políticas para facilitar la incorporación de los ex-toxicómanos al mercado de trabajo (tales como talleres de formación ocupacional), servicios sanitarios para atender las necesidades específicas de los drogodependientes, acciones de prevención (por ejemplo, en las escuelas, a fin de evitar que los adolescentes y los jóvenes se iniciaran en el consumo de las drogas), y medidas para mejorar las condiciones de vida de los toxicómanos que no pueden o no desean abandonar su adicción a las drogas (el suministro de metadona) ${ }^{11}$. Además, las madres han pedido a las autoridades políticas, a quienes trabajan en el Estado tratando con toxicómanos y a los ciudadanos en general que consideraran a quienes consumían drogas como individuos con derechos, y que eliminaran sus actitudes de desdén hacia ellos; estas demandas comprenderían, según Fraser, reivindicaciones de "reconocimiento" positivo de identidades anteriormente despreciadas (Valiente Fernández, en prensa).

\footnotetext{
${ }^{11}$ La metadona es un potente analgésico sintético cuyos efectos anulan el síndrome de abstinencia de los drogodependientes.
} 


\section{LA CLASE SOCIAL: OTRA DIMENSIÓN DE LA IDENTIDAD}

La maternidad no es la única dimensión de la identidad de los miembros de los grupos de madres contra la droga que les ha impulsado a la acción colectiva, si bien ha sido posiblemente la más importante. Como argumento en esta sección, un factor alternativo que ha propulsado a muchas de estas mujeres (no a todas) a la movilización ha consistido en la marcada conciencia de pertenecer a la clase trabajadora o a la clase media-baja.

En las entrevistas realizadas para esta investigación las madres han hablado con frecuencia de su posición socio-económica más bien modesta, y lo han hecho muchas veces de modo espontáneo y sin que fueran preguntadas al respecto. Por ser éstos sus orígenes sociales, las madres han explicado que no podían pagar los escasos tratamientos que el sector privado ofrecía en los años ochenta, por lo que demandaron al Estado que los proporcionara sin coste alguno. Además, las madres han creído que su procedencia social ha hecho que la drogodependencia de sus hijos resultara más visible al escrutinio de otras personas, por comparación con la adicción a las drogas de quienes pertenecen a estratos más acomodados. En opinión de las madres contra la droga, las personas de clase social alta cuentan con opciones que están vedadas a clases más desfavorecidas, entre otras: adquirir y consumir drogas en lugares discretos y no a la vista de toda su comunidad; costear las sustancias adictivas que consumen gracias a sus recursos personales y/o familiares; y acudir a consultas privadas de médicos y participar en programas de rehabilitación alejados de su domicilio. Así, según las madres entrevistadas, las familias de clases acomodadas consiguen, hasta cierto punto, esconder la drogodependencia de sus vástagos de las miradas de sus familiares, vecinos, amigos, conocidos y ciudadanos en general. Por contraste, los drogodependientes de estratos sociales más modestos no pueden sufragar las drogas que requiere su adicción, por lo que han de cometer delitos a fin de conseguir dinero para adquirirlas. Como relataba una madre:

Concha: "El niño este pijito de papá, que la heroína o la coca se la llevan especial, no tiene que salir a robar. El desgraciado como nuestros hijos sí tiene que robar para ello".

Esta madre explicaba, además:

Concha: "Tú date cuenta de que el drogadicto quiere dinero para droga (...). Antes no había la metadona ni había todo esto, pues había madres que con tal de que su hijo no robara les daban [dinero]. Al final ¿qué ha pasado? Que el hijo ha terminado en Carabanchel [una cárcel de Madrid]. ¿Por qué? Porque ningún padre de familia, obreros como nosotros, podemos mantener eso [una drogodependencia] (...)".

De otro lado, con frecuencia los drogodependientes de clase trabajadora han 
adquirido y/o consumido drogas en sus propios barrios. Si han tenido algún problema sanitario, han acudido al médico de cabecera del dispensario público de salud de su zona, también visitado y frecuentado por sus vecinos y conocidos. Por tanto, las madres de clase trabajadora han entendido que no han podido esconder la drogodependencia de sus hijos en las comunidades donde habitan, como, en su opinión, han conseguido hacerlo las familias más acomodadas; por ello, se han movilizado formulando, entre otras demandas, el respeto para sus hijos y para ellas mismas (Valiente Fernández, en prensa). Es preciso mencionar que las mujeres entrevistadas afirmaban conocer no pocos casos de personas que trataban de ocultar la adicción a las drogas de uno de los miembros de su núcleo familiar. Según explicaba una de ellas:

Concha: "Yo he conocido a gente, entonces en Carabanchel [una cárcel de Madrid] se les llevaba la comida. No llevaban los cubos de su casa por que no les viera la gente. Y yo he salido con el cubo de mi casa. ¿Por qué me iba a esconder? Me tocó a mi hijo..."

Por último, algunas madres han explicado en las entrevistas que las personas de clases sociales acomodadas han podido conseguir drogas en un elevado grado de pureza; por el contrario, las de clases modestas han consumido sustancias adictivas muy adulteradas, lo que les ha acarreado serios problemas de salud. Así explicaba esta cuestión una de las mujeres entrevistadas:

Juana: "Porque además, mira, la mayoría de las enfermedades que tienen, no las tendrían. (...) la heroína, o la coca, o lo que hubiera sido, se la dan pura, y no se muere, porque no está adulterada. ¿Cuántos se han muerto por adulteración de la droga? Muchísimos. (...). De SIDA han muerto muchos, pero de sobredosis (...), que la mayoría era porque estaba adulterada, la mayoría. (...). Mi hijo ha muerto de SIDA. Pero ¿tú sabes las enfermedades que ha tenido mi hijo cuando ha muerto? No de SIDA solamente: la circulación, los riñones, (...) el intestino no le funcionaba (...). La porquería que le meten (...). Tú imagínate lo que es meterte en una vena talco. Pues, fijate tú, esas venas, al caer el tiempo, ni circulan. Se les ponen unas heridas ... ¿De qué es eso? De toda la porquería que le dan. Si es pura no les pasa eso. Y la pena que tengo es de no haber tenido dinero para habérsela dado pura, habérsela dado buena para no haber tenido que ir a comprar mierda".

\section{¿QUIÉNES SON LOS EXPERTOS EN DROGODEPENDENCIAS?}

A continuación planteo que la identidad de madre contra la droga adquirida en la acción colectiva de los diversos grupos estudiados incluye la conciencia de poseer un amplio conocimiento sobre drogodependencias derivado de la experiencia personal. Ello no obstante, la interpretación de este conocimiento varía de unas madres a otras. Algunas de las mujeres entrevistadas han 
manifestado que los verdaderos expertos en el tratamiento de las toxicomanías son los diversos profesionales activos en el sector (por ejemplo, psicólogos o trabajadores sociales). Por contraste, otras mujeres han defendido que las expertas en drogodependencias son ellas, y que la interacción con sus hijos toxicómanos en los grupos de madres les ha proporcionado un saber y unas habilidades de que carecen muchos de los profesionales.

Como he apuntado antes, las primeras asociaciones de madres se parecían a los grupos de auto-ayuda, en el sentido de que la mayoría de sus miembros eran mujeres afectadas por una dificultad (la drogodependencia de sus hijos o de otros familiares). A fin de solucionar este problema, las madres trataban de encontrar en las asociaciones la fuerza personal, el apoyo mutuo y la asistencia necesarios, adquiriéndolos al comunicarse con otras madres, compartir con ellas esta experiencia personal y las emociones y sentimientos asociados, y ganar consecuentemente un conocimiento mayor acerca de ellas mismas y de los otros $^{12}$. Estas asociaciones iniciales, además, reivindicaron al Estado políticas relativas a la drogodependencia y proporcionaron servicios personales a los toxicómanos; por ejemplo, trataban de encontrarles alguna plaza en un programa de desintoxicación (Valiente Fernández, en prensa). Sólo contaban con los recursos que ellas mismas generaban a partir de las cuotas que pagaban las socias, además de los que les facilitaban las parroquias donde algunas estaban radicadas.

La naturaleza de los grupos de madres cambió, al menos en un sentido, aproximadamente en los años noventa, cuando comenzaron a recibir subvenciones del Estado. Estos subsidios han sido utilizados por las agrupaciones de distinto modo, si bien muchas de ellas han contratado a profesionales (sobre todo a psicólogos y trabajadores sociales) a fin de que desarrollaran programas para los drogodependientes y los familiares y/o realizaran tareas administrativas y de gestión (por ejemplo, la preparación de la solicitud de nuevas subvenciones). Rápidamente, algunas de estas primeras asociaciones perdieron su carácter de grupos de auto-ayuda, para convertirse en organizaciones en cierta medida lideradas por los profesionales, quienes han enseñado a las madres de qué modo tratar a sus hijos toxicómanos y cómo ayudarles a abandonar la dependencia a las drogas.

Una de las asociaciones investigadas en este estudio sirve para ilustrar claramente el funcionamiento de los grupos de madres dirigidos por los profesionales (y cuyo carácter es, en cierta medida, opuesto al de los grupos formados exclusivamente por madres sin la participación de los expertos). Según los describía la trabajadora social contratada por una de las asociaciones investigadas:

\footnotetext{
${ }^{12}$ Esta definición de los grupos de auto-ayuda procede, en parte, de: Jary y Jary (1991:437).
} 
Marta: "Aquí hay dos grupos complementarios: el grupo de apoyo psicológico, y después el grupo de animación socio-cultural. (...). El grupo de apoyo psicológico (...) lo atiende, lo lleva, una psicóloga que nos mandan de la Federación [de agrupaciones de madres]. Este grupo de apoyo es, cuando llega una familia con el problema latente, con su hijo en casa consumiendo [drogas], no sabe qué hacer. En ese grupo la forman, la preparan para dotarse de recursos para enfrentar ese problema: (...) normas, límites, cómo hablar al hijo, qué permitirle, qué no permitirle, (...). Ahí se trabaja el problema con una psicóloga. Y el complementario es el grupo de animación socio-cultural, donde, al margen del problema de la droga, eso se intenta dejar a un lado, y se trabaja con ellas la auto-estima, la relajación, que vuelvan a pensar en ellas mismas, en su marido, en sus otros hijos, que no centren el problema en el hijo drogodependiente, que ellas tienen una vida sobre la que pueden poner soluciones; sobre la de su hijo las tiene que poner él, ellas pueden apoyar. Pero tienen que tener muy presente que es la vida de su hijo (...).

Entrevistadora: ¿Y quién lleva ese grupo de animación socio-cultural?

Marta: El de animación socio-cultural, una animadora socio-cultural".

En los grupos, y en otros lugares, las madres ya habían comprendido que sus hijos no dejarían de consumir sustancias adictivas si ellos mismos no tenían la firme voluntad de alcanzar este objetivo. Los profesionales aconsejaron a los miembros de los grupos que no se limitaran a buscarles programas y/o centros de desintoxicación y rehabilitación y animarles a acudir a ellos; también era preciso que, mientras los toxicómanos vivieran en el hogar familiar, les instasen con decisión a seguir horarios regulares respecto de las comidas y las horas de llegada a casa por las noches (entre otras cuestiones). Los expertos les recomendaron además que no les proporcionaran dinero para comprar drogas ${ }^{13}$. Los expertos animaron a las madres a que, en última instancia, si sus hijos drogodependientes no hacían esfuerzos sinceros por abandonar el consumo de sustancias adictivas y deterioraban gravemente la convivencia familiar, les expulsaran del hogar y sólo les permitieran volver a él si albergaban seriamente el propósito de superar su toxicomanía. Estas recomendaciones resultaron muy valiosas en algunos casos, pues según han afirmado ciertas madres en las entrevistas, no habían sabido cómo actuar cuando descubrieron la drogodependencia de sus hijos. Según explicaba una de ellas:

\footnotetext{
${ }^{13}$ Algunas madres han descrito en las entrevistas que cuando sus hijos se convirtieron en adictos a las drogas dejaron de vivir siguiendo horarios regulares (véase infra) y de cuidar su aseo personal como lo habían hecho antes. Además, trataban por todos los medios de conseguir dinero para comprar sustancias adictivas. Cabe apuntar que estas pautas de comportamiento son propias de un número no desdeñable de drogodependientes, pero no de todos ellos.
} 
Aurora: "Cuando no sabes, como al principio, que yo no sabía que iba a hacer. 'Me ha caído este problema así de golpe y: ¿Cómo salgo yo de esto? No sé para dónde tirar"'.

Esta misma madre describía cómo siguió algunos de los consejos brindados por los profesionales:

Aurora: "Eso me inculcaron mucho: firmeza, firmeza y firmeza.

Entrevistadora: Pero eso debe ser muy dificil.

Aurora: ¡Hombre, claro que lo es! Muy difícil es. Pero da resultados. Si consigues mantenerte. (...). En horarios, permitirla los horarios. Era muy importante. Entonces (...) [la psicóloga] me dijo: 'Tú, ¿a qué hora consideras, hasta qué hora consideras...' Digo: 'Como muy tarde, a las once y media o a las doce'. (...). Y dice [la psicóloga]: 'Bueno, pues si llegada esta hora, ella [la hija drogodependiente] no está en casa, no la dejas entrar'. Entonces, así lo estaba haciendo. $\mathrm{Y}$ me ha tocado muchas noches tenerla alli enfrente de mi casa, oyéndola toser, llorar, lo que sea; y sentada allí, porque hay una valla, que es un colegio de monjas, y hay una valla que tiene poyete, así, en la pared, a una altura así. Se sentaba allí, y de frente estaba mi dormitorio, mi habitación. Y yo dejaba la persiana con rendijitas para ver. De cuando en cuando me levantaba. (...). Se ponía en la puerta, en el este de la puerta, hasta ver si algún vecino de éstos que suelen venir muy tarde... Y ya se metía, pero claro, no se metía en casa, porque en casa no podía. Se quedaba en la escalera. Yo lo sabía, que estaba en la escalera. Pero: 'Ahí te estás, ahí te estás en la escalera'. (...). En las comidas, igual. Por las mañanas, que [la hija toxicómana y su pareja] se salían [a la calle] muchas veces. 'Aquí se come a tal hora. Si tú a esta hora no estás aquí, ya sabes que se ha acabado la comida'. Así que en eso también. Porque, igual, venían a comer a la hora que querían, a las cuatro, a las cinco, a las seis, cuando a ellos les venía bien. Tú habías comido pero ellos llegaban y ¡hala! ¡a comer! No había horarios para nada".

Algunos expertos (pero no todos) entendían que algunas madres no iban a seguir sus consejos al pie de la letra, por lo que les sugirieron que marcasen a sus hijos sólo los límites que fueran a mantener realmente. En palabras de la trabajadora social contratada por una de las asociaciones:

Marta: "Siempre las decimos, por ejemplo, que hasta donde puedan llegar. O sea, hay límites que si ven que no van a poder cumplir, es mejor ni siquiera intentarlo, porque las amenazas por amenazar, es lo peor que hay. $\mathrm{O}$ sea, decir: 'Te voy a echar'. 'Te voy a echar' [de casa]. 'Te voy a echar', y no hacerlo nunca (...). Porque no es echar, es dar a elegir un camino. Lo pueden interpretar como quieran, pero no es echar. Pero bueno, que si no puedes cumplir ese límite, mejor no decirlo siquiera'".

Las madres eran conscientes de las enormes dificultades y esfuerzos que 
acarreaba seguir las mencionadas recomendaciones de los expertos. Una de ellas lo expresaba de este modo:

Clara: "Consideramos que la teoria es muy bonita, en la práctica todos queremos llevarla a cabo, pero la verdad es que se rompen todos los esquemas cuando te enfrentas a un problema de este tipo. (...). Pensándolo en frío todos sabemos la teoría, todos sabemos lo que hay que hacer, lo que pasa es que cuando llega una situación de este tipo te encuentras con una persona que ... enfermo, que están muy pirados, y además, más pirado que enfermo. Muy pirado, y entonces, como está muy pirado, llega un momento en que ya no sabes si la que estás pirada eres tú, él, (...)".

Un segundo tipo de mujeres entrevistadas está constituido por aquéllas que aceptan la profesionalidad de los expertos (pero no la de todos ellos), opinan que la han ganado con el paso del tiempo (porque antes no contaban con ella), pero piensan además que las madres también saben mucho acerca de la drogodependencia, lo cual les ha permitido en ocasiones corregir a los profesionales, pese a que el nivel educativo formal alcanzado por éstos es considerablemente más elevado que el de ellas. Así lo explicaba una madre, tras destacar que la trabajadora social que su asociación había contratado realizaba una valiosa labor, especialmente encargándose de los trámites burocráticos y administrativos:

Encarnación: "El principio de la asociación, mira, yo estaba en el Ayuntamiento, estuve cuatro años en el Ayuntamiento, yendo a las reuniones. Entonces los psicólogos no sabían tanto ahora como sabe la gente. Entonces a los psicólogos se los ... yo como tenía mucha experiencia, yo les decía que no, que lo que estaban diciendo, que no, que así no era y que no. Lo mismo que yo, otras madres. (...). Yo estaba con Zenaida [una psicóloga]. Zenaida era la que llevaba lo del Ayuntamiento, apuntaba a los chicos, y los chicos se esperaban allí mucho, mucho y no les daban las granjas [un tipo de centro de deshabituación a las drogas], porque los chicos querían las granjas. (...). Entonces, yo, a lo primero estaba un poco... pero luego ya un día me fui metiendo y ya un día entré con ella y le dije que no podia ser lo que estaba haciendo. Y me dice: '¿Pues qué estoy haciendo?' Digo: 'Mira, ¡si vieras como te están poniendo!'

Entrevistadora: ¿Los chicos?

Encarnación: Los chicos. 'No lo ibas a consentir', digo 'Lo mismo mi hijo ¿eh?, y con razón, y con razón. Porque no se puede tener aquí a un chico seis meses, y venga, y venga, y mándale todos los días. Así que, de eso te tienes que olvidar un poco o hacer lo que sea"'.

El conocimiento de estas madres acerca de las toxicomanías hace, por 
ejemplo, que sepan reconocer, por signos externos, si una persona ha consumido (o no) drogas:

Benigna: "En el andar.
Encarnación: En el andar.

Benigna: Incluso cuando entra [en la sede de la asociación] y le ves, dices: 'Ése se sigue drogando'. Va andando... va andando...

Entrevistadora: ¿Sí?

Benigna: Sí, va andando como dando saltitos (...)".

Por contraste, otras madres pensaban que las expertas en tratar con los drogodependientes eran ellas y no los profesionales, por haber aprendido de la observación y el contacto con casos reales. Procesos semejantes de adquisición de experiencia a partir del conocimiento personal y directo con un problema determinado han sido documentados por la investigación internacional acerca de otros movimientos sociales, por ejemplo, la movilización contra el SIDA en Estados Unidos (AIDS movement) (Epstein, 1998). Gracias al saber y las habilidades de este modo conseguidos, dicho movimiento ha logrado ejercer una amplia influencia en la investigación y práctica médicas en Norteamérica. Si bien las madres contra la droga posiblemente no han imprimido un ascendiente similar en las políticas relativas a estas adicciones, merece la pena detenerse, siquiera brevemente, en el estudio de la adquisición de esta especialización práctica en el tratamiento de las toxicomanías, porque ha vertebrado la construcción de la identidad de algunos miembros de las asociaciones estudiadas. Como relataba una madre:

Juana: "Yo en cierta ocasión, hace ya muchos años ¿eh?, a una psicóloga le dije estas palabras: 'Tú a mí no me puedes enseñar nada, yo a ti sí' (...). Porque no es igual estar en el problema que verlo de la calle".

De igual parecer era otro miembro de una de las asociaciones investigadas:

Matilde: "Los expertos, cuando han venido aquí a las asociaciones, los 'expertos', no sabían ni papa; han aprendido de nosotros. O sea, que los expertos no existen. Eso es un cuento chino".

Esta madre, no obstante, sí conversó sobre la drogodependencia de su hija con un psicólogo amigo de aquélla, manifestando que estos diálogos le 
resultaron de gran ayuda:

Matilde: "Con él sí me valía, porque hablábamos de persona a persona. Me decía: 'Mira, deja de hacerte pajas mentales [acerca de la posibilidad de que ella fuera culpable de la toxicomanía de su hija], que esto no es así'. Me hablaba llanamente y me contaba, o sea ... 'Pues ahora mismo, pues tu hija ha sido una catacaldos como cada uno de nosotros hemos catado, y he probado de todo (...)'".

Una de las madres explicaba que, llevada por el deseo de saber más acerca de la dependencia a las sustancias adictivas, había observado a su hijo inyectarse drogas, e incluso pensó consumirlas ella misma:

Juana: "Porque yo he visto a mi hijo pincharse.

Entrevistadora: ¿Tú le has visto?

Juana: Yo le he visto pincharse, yo. He tenido el ese de querer ver y querer saber. Y yo te digo una cosa, que más de cuatro veces he estado por probarlo [las drogas], sí. Más de cuatro veces, porque yo quería saber, yo quería saber, pero yo decía: '¿Por qué?', el por qué no pueden salir. $\mathrm{Y}$ a fuerza de estar viéndolo, porque yo he visto a mi hijo montones de veces, sin que él me viera, he estado observándole cuando se ha pinchado (...) sin que él me viera. Si él me ve no lo hace. (...). La habitación que tenía él tenía una ventanita al patio, y yo por la ventanita del patio le he estado observando cuando se pinchaba montones de veces: la reacción que tenía, lo que hacía, (...).

Entrevistadora: ¿Se pinchaba en casa? Porque otra gente no lo hacía.

Juana: Sí, sí, muchas veces. Nosotros, como vivíamos los dos solos, tenía más libertad, porque yo (...) incluso le decía ¿tienes que irte por ahí a la calle? que sabes que eso no es más que enfermedades y guarrería, (...)'. Y claro, pues se lo hacía mucho en casa. Aunque también lo ha hecho por ahí, y prueba de ello es que ha enfermado [de SIDA], que tampoco sé si ha sido por la aguja o ha sido por el sexo, no sé más que que enfermó (...)'.

Más adelante, esta misma madre describía las reacciones inmediatas durante y después del acto de consumir drogas:

Juana: "Es de alucinar, verles ponérsela. No te lo puedes ni imaginar (...) lo que es, estar que ni atina siquiera a ponérsela, ni a preparárselo siquiera de los nervios, que están temblando (...). Y es ponerse la aguja, es que es pinchársela y ya han cambiado de cara. Y según se la van empujando, la jeringuilla, vas viendo la cara que le va cambiando; los ojos, porque se les ponen unos ojos cristalinos, unos ojos sin vida (...) es que les cambia todo, por segundos (...). Y luego llega un momento en que no tienen nada en la jeringuilla, otra 
cosa que es que todo el mundo no sabe eso, pero ya te digo que yo lo he observado y lo he vivido. No tener nada en la jeringuilla y quedarse con la aguja puesta y de vez en cuando mover la aguja. ¿Tú sabes qué sensación? ¿Tú sabes la sensación que a mí me, dirás ¡qué barbaridad! mal comparado, pues una persona que está haciendo el amor y le viene... está en el momento cumbre ¿no? Solamente moverse la aguja ahí, el aspecto de cara, eso lo he visto yo, a mi hijo".

No sorprende, por tanto, que estas mujeres, que pensaban que las expertas eran ellas y no los profesionales, no siguieran algunos de sus consejos (si bien trataron de poner en práctica otros). Esta madre relataba que nunca expulsó a su hijo del hogar, tal como le instaban; además, le daba dinero para comprar sustancias adictivas, e incluso en alguna ocasión las adquirió ella misma para él:

Juana: "Yo conocía a mi hijo (...) y yo dije (...): 'No sale de la droga mi hijo, no sale'. Lo vi clarísimo desde el principio. Y claro, nos aconsejaban (...) los psicólogos que los echáramos a la calle, y yo nunca lo he echado. Y me decían: 'Pero claro, si tú no le ayudas, no se va a quitar nunca'. (...). Y les decía: 'Lo que me estás diciendo no lo voy a hacer'. 'Es que es conveniente, es que si no lo haces, es que ...' 'Sí, pero es que, primero, no tengo valor para hacerlo'. Porque es que, mira, si por casualidad hubiera sido agresivo, él me hubiera pegado, él me hubiera contestado, él me hubiera ... pues a lo mejor me había dado fuerza para coger y decirle: 'Mira, ahí estás en la puerta de la calle y no vuelvas a poner los pies más ... porque no te lo consiento'. Pero es que a mí jamás me ha dado una mala contestación. (...). Es que, en principio, ¿cómo vas a echar a un hijo que no te contesta, que no te da una voz (...), nada, al revés. 'Mamá, si llevas razón, si es verdad, si es que te estoy quitando la vida, pero mamá, si es que no puedo' (...). !Bueno! pues yo incluso he ido a por droga, a comprarla. Y yo le he dado el dinero para comprarla. Y yo me hice el propósito: (...) mientras que yo tenga dinero, mi hijo no va a robar a nadie. Él la necesita. Si él no tiene dinero, él tiene que sacarlo de algún sitio. $Y$ que yo tenga dinero y que vaya a robar a una señora que pasa por ahí, por la calle, yo soy incapaz de consentir eso. (...). He cogido incluso a compañeros (de la asociación), estar en una reunión, y venir desesperado, y decirle: 'Antonio, ¿me puedes llevar a (...) [cita un barrio de Madrid donde se vendía droga]?' 'Venga, sí, te acompaño'. E ir con este vecino, o sea, con este padre, (...) a comprar la droga para mi hijo'.

Más adelante en la conversación, esta madre puntualizaba:

Entrevistadora: "¿Y qué te decían las psicólogas cuando tú les decías: 'Miren, es que mi hijo no va a salir...'

Juana: 'Eso tú no lo sabes'. Bueno, pues yo eso no lo sabré, pero el convencimiento que tengo yo es ése. Y yo no le ayudo a que vaya. Yo intento por todos los medios que se 
RIS

REVISTA NTERNACIONAL DE SOCIOLOGIA

№ 29, Mayo - Agosto, 2001

quite. De hecho yo le busco granjas. En el momento que él pedía ayuda, que decía: 'Mamá'. Claro, yo no le podía empujar, no podía obligarle, no vale de nada. Pero si él me decía: 'Mamá, ayúdame'. '¿Qué quieres que te haga? Tú explícame qué es lo que quieres. Tú sabes, yo te ayudo, a lo que tú quieras'".

Estas madres, que no creían en la superioridad del conocimiento de los profesionales (por comparación con el adquirido por ellas), también dudaban, en general, de la utilidad de los consejos elaborados por aquéllos; acerca de la recomendación de expulsar a los hijos del hogar familiar si no dejaban de consumir drogas, la misma entrevistada afirmaba:

Juana: "Lo han hecho muchas y ¿de qué les ha servido? (...) Verónica, la que ha entrado aquí ahora mismo, (...) te lo habrá contado, estaba en la calle, el hijo en su casa ha estado muy pocas veces. Se ha cambiado hasta de casa, para que no supiera donde vive y ¿de qué le ha servido? Pues su hijo está debajo de la tierra como el mío. Su hijo no se ha quitado de la droga. Su hijo ha estado tirado en la calle, y el mío ha estado en mi casa, así de claro, y yo lo que quería era eso. Punto. Yo respeto las opiniones y lo que haya hecho cada madre; yo lo respeto, cuidado, han tenido valor para hacerlo. (...) De todas las que estamos aquí, no le ha servido a ninguna, a ninguna. A ver, preséntame a una que diga: 'Aquí está mi hijo'. En la asociación yo creo que no hay nada más que dos personas, de la asociación, de las antiguas, que yo pueda decir que han salido los hijos".

Es preciso destacar que los subsidios estatales no son el único factor que explica la aparición de los profesionales en los grupos de madres contra la droga, y su potencial competición con éstas por el estatus de personas versadas en la adicción a las toxicomanías. En los años ochenta, cuando surgieron las primeras agrupaciones de que trata este artículo, el Estado y la sociedad civil apenas ofertaban servicios para las personas que consumían drogas. Por contraste, en la actualidad las autoridades públicas y las asociaciones voluntarias de diverso tipo (con ayuda de dinero estatal) gestionan programas para los drogodependientes y sus familias. Los destinados a los familiares (cuya aparición es claramente posterior al surgimiento de los primeros grupos de madres) han estado, desde el principio, dirigidos por profesionales, quienes presiden las reuniones y aconsejan a las personas que a ellas asisten. En algunos casos, cuando las actividades planeadas se han llevado a cabo y han concluido, ciertas madres que sentían la necesidad de continuar la interacción con otros progenitores (por lo general, también madres) han formado, junto con algún profesional, un grupo de familiares contra la droga. De èsta forma se ha gestado una de las asociaciones analizadas en este trabajo.

Sólo una de las agrupaciones investigadas, "Madres Unidas", ha decidido no recibir subvenciones del Estado (con alguna excepción). Ha rechazado los subsidios por entender que, en general, domestican a las agrupaciones; estas 
madres han deseado tener las manos libres para poder movilizarse en contrade las políticas públicas relativas a la drogodependencia que consideraran inadecuadas, así como para denunciar los abusos cometidos contra los toxicómanos. En alguna de las entrevistas, los miembros de otros grupos que reciben ayudas públicas reconocían que en ocasiones las subvenciones inhiben a las organizaciones de las acciones reivindicativas; léanse, a modo de ilustración, las siguientes manifestaciones:

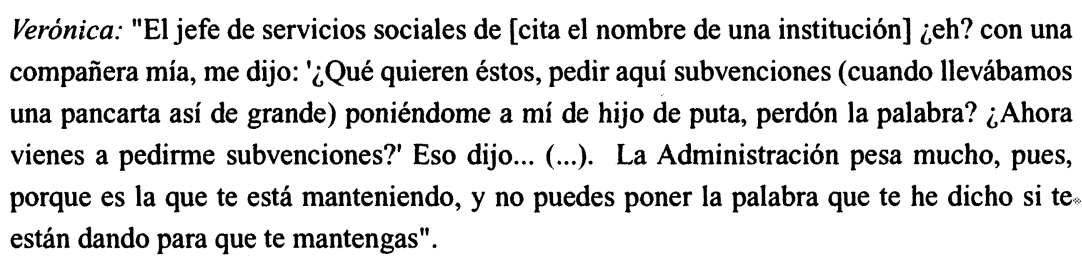

\section{CONCLUSIONES}

En general, los estudios sobre movimientos de madres han tendido a presentar a éstas como mujeres que, impulsadas por lo que Kaplan denominó "conciencia femenina", se movilizan persiguiendo "intereses prácticos de género" (según la terminología de Molyneaux), esto es, la mejora de las condiciones materiales en que viven sus familias, y en algunas ocasiones el respeto de los derechos humanos. De otro lado, si bien la literatura sobre la "redistribución" y el "reconocimiento" (conceptos acuñados por Fraser) no suele aplicarse al estudio de este tipo de movimientos, este artículo ha mostrado que se trata de un marco analítico útil para investigarlos, porque nos ayuda a entender que la acción colectiva de estas madres no sólo trata de alcanzar metas económicas; otras dimensiones, menos evidentes, pero claves de su movilización, se centran en los aspectos identitarios. Este escrito ha puesto de manifiesto que la forja de una identidad colectiva constituye un objetivo que no es exclusivo de los movimientos tradicionalmente estudiados como centrados en las cuestiones de identidad entre otros, ciertas corrientes del movimiento organizado a favor de los derechos de los homosexuales, las mujeres o los miembros de algunas comunidades étnicas. Las asociaciones analizadas en este trabajo han desarrollado una identidad de madre contra la droga, cuyo perfil es el de ser una persona que, si tiene un hijo drogodependiente, puede revelarlo ante la comunidad, no se siente culpable por tal drogodependencia, no es necesariamente la madre biológica de un individuo que consume sustancias adictivas, y es consciente de pertenecer a una clase social modesta y de poseer un amplio conocimiento sobre la adicción a las drogas (que le lleva, en algunos casos, a argumentar que ella es la auténtica experta en la materia, y no los profesionales). 
En otras palabras, las madres contra la droga han intentado (y posiblemente conseguido) convertir esta condición en una identidad positiva y combatir que fuera conceptualizada como un estigma (Goffman, [1963] 1995).

Esta investigación también ha documentado que los problemas sociales son realidades percibidas de manera selectiva por quienes se movilizan. Los participantes de la acción colectiva definen algunas circunstancias como intolerables y, para modificarlas, se esfuerzan de manera concertada. Así ha sucedido a muchas madres contra la droga respecto de su presunta culpa por la drogodependencia de sus hijos, ya que han superado este sentimiento gracias a su participación en las asociaciones. Por el contrario, otras condiciones pueden no resultar satisfactorias, pero son conceptualizadas como soportables. En este sentido, tal vez a algunas de estas madres no les gustara que las subvenciones recibidas por sus asociaciones mitigaran sus actividades reivindicativas, pero decidieron pagar este precio a fin de dotar a sus grupos de recursos con los que reforzar su acción colectiva.

Los hallazgos de este estudio también sugieren líneas de investigación para ser desarrolladas en el futuro. Este trabajo no ha analizado si la movilización de las madres contra la droga es diferente según sean los hijos o las hijas quienes consumen drogas. El bajo número de mujeres con hijas toxicómanas entrevistadas (tres) no ha hecho posible identificar pauta alguna. Me resultó difícil encontrarlas, y esta dificultad puede reflejar el hecho de que el número de mujeres que toman drogas es inferior al de hombres. Ello no obstante, cabe preguntar si quizá puede indicar, también, que las madres participan más (o más activamente) en los grupos aquí analizados cuando sus hijos consumen drogas que cuando lo hacen sus hijas. Tal vez la relación de las madres y los hijos contiene algún ingrediente especial, del que carece el vínculo con las hijas, o acaso las madres perciben que el honor, el prestigio y el éxito de la familia como grupo corren más peligro cuando los hijos, por comparación con las hijas, tienen un problema de dependencia a las sustancias adictivas. También pudiera ser distinto el tipo de deshonra que la familia en conjunto experimenta con los comportamientos que se asocian a algunos drogodependientes según el género. Me sorprendió que no pocas madres entrevistadas se refirieran a los robos perpetrados por sus hijos (varones) para conseguir dinero con el que comprar drogas, y que lo hicieran con bastante franqueza, de modo espontáneo y sin ser preguntadas al respecto. Por contraste, las madres no mencionaban la prostitución como un medio utilizado por más toxicómanas que toxicómanos para obtener ingresos con que financiar su adicción. Con alguna excepción, no conversaron sobre el tema; no lo hicieron ni quienes tenían o habían tenido hijas drogodependientes ni las restantes madres, incluso cuando les pedí explícitamente que departieran conmigo sobre la cuestión.

Por otro lado, este trabajo ha mostrado que, en general, los miembros de los grupos de madres contra la droga han encontrado la pertenencia a estas 
asociaciones útil en muchos sentidos. Sin embargo, este hecho no debe hacernos olvidar que la mayoría de las madres de drogodependientes no participan en este tipo de organizaciones. Como he apuntado antes, son muchas las diferencias que separan a las integrantes de estas asociaciones; quizá estas diferencias dificultan o impiden a muchas mujeres militar en estos grupos. En realidad, no sabemos prácticamente nada acerca de cómo las madres que no están asociadas se enfrentan al problema de la drogodependencia de sus hijos, ni por qué no se unen a las agrupaciones estudiadas aquí. Estas y otras cuestiones habrán de abordarse en el futuro, posiblemente desde diferentes perspectivas de análisis, entre ellas el estudio de los movimientos sociales, las familias, el género o los problemas sociales en general.

\section{Asociaciones donde fueron realizadas las entrevistas}

Asociación Adelfa, Madrid; Asociación de Lucha Antidroga-Latina (ALADLatina), Madrid; Asociación de Padres, Familiares y Amigos del Drogodependiente la Esperanza (ASPAFADES), Madrid; Asociación de Padres de Drogadictos (ASPAD), Madrid; Asociación para la Prevención y Rehabilitación de Drogadictos (APYRD), Madrid; Asociación Por Una Nueva Vida (PUNVI), Madrid; Asociación Tú Puedes, Fuenlabrada (Madrid); Madres Unidas Contra la Droga, Madrid.

\section{REFERENCIAS}

ALVAREZ, S. (1990), Engendering Democracy in Brazil: Women's Movements in Transition Politics, Princeton (New Jersey), Princeton University Press.

CENTRO DE INVESTIGACIONES SOCIOLÓGICAS (2000), Estudio número 2.387, marzo, datos disponibles el 22 de mayo de 2000 en http://www.cis.es/baros/mar2387.htm.

CHRISTIANSEN-RUFFMAN, L. (1995), "Women's Conceptions of the Political: Three Canadian Women's Organizations", en M. M. Ferree y P. Y. Martin (coords.), Feminist Organizations: Harvest of the New Women's Movement, Filadelfia, Temple University Press, pp. 372-393.

DELLA PORTA, D. y M. DIANI (1999), Social Movements: An Introduction, Oxford, Blackwell.

DIANI, M. (1992), "The Concept of Social Movement", Sociological Review, 40, pp. 1-25.

ELZO, J., F.A. ORIZO, J. GONZÁLEZ-ANLEO, P. GONZÁLEZ, M.T. LAESPADA y L. SALAZAR (1999), Jóvenes españoles 99, Madrid, Fundación Santa María.

EPSTEIN, S. (1998), Impure Science: Aids, Activism, and the Politics of Knowledge, Berkeley, University of California Press. 
FRASER, N. (1995), "From Redistribution to Recognition? Dilemmas of Justice in a 'Post-Socialist' Age", New Left Review, 212, pp. 68-93.

GOFFMAN, E. ([1963] 1995), Estigma: La identidad deteriorada, Buenos Aires, Amorrortu.

GORDON, L. (1994), Pitied But Not Entitled: Single Mothers and the History of Welfare, Nueva York, Free Press.

HONNETH, A, (1992), "Integrity and Disrespect: Principles of a Conception of Morality Based on the Theory of Recognition", Political Theory, vol. 20, $\mathrm{n}^{\circ} 2$, pp. 187-201.

JAQUETTE, J. S. (coord.) (1994), The Women's Movement in Latin America: Participation and Democracy, Boulder (Colorado), Westview Press.

JAQUETTE, J.S. y S.L. WOLCHIK (coords.) (1998), Women and Democracy: Latin America and Central and Eastern Europe, Baltimore, Johns Hopkins University Press.

JARY, D. y J. JARY (1991), The HarperCollins Dictionary of Sociology, Nueva York, HarperPerennial.

KAPLAN, T. (1982), "Female Consciousness and Collective Action: the Case of Barcelona, 1910-1918", en N. O. Keohane, M. Z. Rosaldo y B. C. Gelpi (coords.), Feminist Theory: A Critique to Ideology, Brighton, Harvester Press, pp. 55-76.

(1997), Crazy for Democracy: Women in Grassroots Movements, Nueva York y Londres, Routledge.

(1999), "Luchar por la Democracia: Formas de organización de las mujeres entre los años cincuenta y los años setenta", en A. AGUADO (coord.), Mujeres, regulación de conflictos sociales y cultura de la paz, Valencia, Universitat de València, pp. 89-107.

KOVEN, S. y S. MICHEL (1990), "Womanly Duties: Maternalist Politics and the Origins of Welfare States in France, Germany, Great Britain, and the United States, 1880-1920", The American Historical Review, $\mathrm{n}^{\circ}$ 4, pp. 1076-1108.

(coords.) (1993), Mothers of the New World: Maternalist Politics and the Origins of the Welfare State, Nueva York, Routledge.

LIJPHART, A. (1971), "Comparative Politics and the Comparative Method", American Political Science Review, vol. 65, pp. 682-693.

MARTÍN SERRANO, M. (1996), Informe Juventud en España 1996: Avance de Resultados (Septiembre 1996), Madrid, Instituto de la Juventud.

McADAM, D. (1982), Political Process and the Development of Black Insurgency, 1930-1970, Chicago, University of Chicago Press.

MILES, A.R. (1996), Integrative Feminisms: Building Global Visions, 1960s-1990s, Nueva York y Londres, Routledge.

64 
MOLYNEAUX, M. (1985), "Mobilization without Emancipation? Women's Interests, the State, and Revolution in Nicaragua", Feminist Studies, vol. 11, n 2, pp. 227-254.

MUNCY, R. (1991), Creating a Female Dominion in American Reform, 1890-1935, Nueva York, Oxford University Press.

PARDO, M. (1995), "Doing It for the Kids: Mexican American Community Activists, Border Feminists?", en M. M. Ferree y P. Y. Martin (coords.), Feminist Organizations: Harvest of the New Women's Movement, Filadelfia, Temple University Press, pp. 356-371.

PEDERSEN, S. (1993), Family, Dependence, and the Origins of the Welfare State: Britain and France, 1914-1945, Nueva York, Cambridge University Press.

SCHIRMER, J. (1993), "The Seeking of Truth and the Gendering of Consciousness: The CoMadres of El Salvador and the CONAVIGUA Widows of Guatemala", en S.A. Radcliffe y S. Westwood (coords.), Women and Popular Protest in Latin America, Londres y Nueva York, Routledge, pp. 30-64.

SKOCPOL, T. (1992), Protecting Soldiers and Mothers: The Political Origins of Social Policy in the United States, Cambridge (Massachusetts), Harvard University Press.

SKOCPOL, T., M. ABEND-WEIN, C. HOWARD y S.G. LEHMANN (1993), "Women's Associations and the Enactment of Mother's Pensions in the United States", American Political Science Review, vol. 87, $\mathrm{n}^{\circ} 3$, pp. 686-701.

TAYLOR, Ch. (1992), Multiculturalism and "The Politics of Recognition", Princeton, Princeton University Press.

VALIENTÉ FERNÁNDEZ, C. (en prensa), "Mobilizing for Recognition and Redistribution on Behalf of Others? The Case of Mothers against Drugs in Spain", en B. Hobson (coord.), Gender, Political Identities and Recognition Struggles in Contemporary Societies, Estocolmo.

YOUNG, I.M. (1990), Justice and the Politics of Difference, Princeton (New Jersey), Princeton University Press. 